\title{
Performance study of Photocatalysis on the degradation of Lignin from Pulp and Paper industry wastewater
}

\author{
Shantanu N. Pawar \\ Research Student, Civil Engineering Department, \\ SSBT's College of Engineering and Technology, Jalgaon, Maharashtra, India \\ Dr. Mujahid Husain \\ Professor and Head, Civil Engineering Department, \\ SSBT's College of Engineering and Technology, Jalgaon, Maharashtra, India
}

\begin{abstract}
Lignin, being major contaminant in pulp and paper mill effluents, cannot be efficiently and economically removed by conventional treatment processes. Photocatalysis is a natural process of pollutant degradation in water. It has proven wide application potential in the field of water and wastewater treatment. This paper describes the performance study of Photocatalysis on the degradation of Lignin from Pulp and Paper industry wastewater. Experimentations were conducted on pure Lignin- water media to evaluate the performance of photocatalytic slurry phase reactor for Lignin oxidation. Experimentations were conducted for $\mathrm{pH}$ and Catalyst dose optimization. It has been found that most rapid oxidation is achieved at $\mathrm{pH}$ 5.5. A catalyst concentration of $2000 \mathrm{mg} / \mathrm{l}$ has optimised oxidation potential for $2 \%$ Ligninwater solution for 2 Hours of UV exposure. Utilizing the obtained optimistic values, other operational parameters can be evaluated for modeling the Photocatalytic Reactor.
\end{abstract}

Keywords - Photocatalysis, Pulp and Paper mill wastewater, Slurry phase reactor, UV/TiO

\section{INTRODUCTION}

Traditionally, the water contained impurities which were removed easily by conventional technology. The wastewaters also contained organic bio-degradable impurities that were removed by biological treatment. However with the development of science and technology, industrialization and changed life style, the wastewater characteristics also have changed. Today, industrial and domestic wastewaters contain huge amount of nonbiodegradable organics. They cannot be removed by biological methods. They are finding way into drinking water sources and are also joining the food chain.

Photo-catalysis is the only viable and economically feasible option for the removal of non-biodegradable organics. The technology is being used for wastewaters as well as for waters also. The technology was developed in 1970s with the pioneer works of Fujishima (1972). Today it is one of the most preferred areas of research in wastewater treatment.

The present work has proposed to remove Lignin from the wastewater using this technology. Lignin is a long chain organic polymer found in the wastewaters of pulp and paper industries. It is non-biodegradable. The conventional techniques used for the removal of lignin are adsorption, RO etc. they simply change the phase of the problem but does not solve it. Researchers have also used fungi for the treatment of lignin. Yet its separation from the wastewater is very difficult. Moreover the process is slow and too sensitive.

Photo-catalysis is a robust, effective and economically viable technology for such type of wastewaters. Little research work is available till now in this regard. The present work is for the removal of lignin using photo-catalysis technology. The technology will be used in the slurry phase reactor. The design parameters of the reactor and operational parameters of the process will be investigated.

\section{RELATED WORK}

The basic process of photo-catalysis has been explored deeply by researchers. Phenol has remained as the first choice of earlier researchers as a probe chemical for degradation. Alberici et. al. (1997) have used this technology for removal of VOCs. Brillas et. al. (1998) presented a scientific look into the process and described the electron transfer phenomenon. Augugliaro et. al. (1999) and Cao et. al. (2000) applied the process for treatment of Toluene 
in gaseous phase. Alex et. al. (2003) used this technology for removal of benzoic acids using specially designed cascade reactor configuration. Later researchers showed interest in the investigations of formation of intermediate products of the process too as stated by Pal et. al.(2000). Al Hakimi et. al. (2003) applied photo-catalysis technology for treatment of industrial wastewaters. Alpert et. al. (1991) treated hazardous waste using photocatalysis. Researchers are working on developing composites of Titanium having even better performances. Ananta et. al. (2003) have reported development of Zirconium Titanate thin film for photo-catalysis. The use of photocatalysis for removal of Halogenated Compounds had started as early as in 1970s. Carey et. al. (1976) reported the degradation of Polychlorinated Biphenyls and Barbeni et. al. (1985) reported the degradation of Penta-ChloroPhenol Chlorinated using slurry phase reactors. Leprot et. al. (1993) have used degraded propanol by the Photocatalysis method. The use of this process for disinfection of waters has been used since 1990s. Domenech et. al. (1993) have reported the application of photo-catalysis for disinfection of waters. Researchers also explored a variety of innovative configurations to apply the technology. Bedford et. al. (1994) proposed a new concept of shallow pond like reactor facilitated with solar concentrators. Husain et. al. (2000) proposed a combined system for photo-catalytic and photo-thermal applications. Zhang et. al. (2001) has proposed a rotating drum based reactor for the film phase process.

The technology has been applied for a variety of wastewaters. Muradov et. al. (1994) applied the technology for treatment of extremely explosive substance Nitro-Glycerin. Beckbolet (1996) used this technology for treatment of landfill leachates. Minero et. al. (1996) degraded Atrazine using Photo-catalysis process. Black Daneil (1996) and Goswami et. al. (1998) have presented a Bibliography of the work done by researchers to us this technology for Air and Water purification. The kinetic studies of the process have been done by many workers. Boudart et. al. (1984), Hussain et. al. (1988), Sabate et. al. (1991) and Jose et. al. (1993) have proposed few initial models to describe the kinetics of the photo-degradation process. Black et. al. (1991) have given bibliography of kinetic models describing the composite behavior of the process. Klausner et. al. (1994) have determined the reaction rate constants for the process using curve fitting techniques. Louis et. al. (1996) described the effect of operating parameters like temperature etc. on the photo-degradation process using Ethylene as a probe chemical. Photo-catalysis has been widely used in the degradation of Azo-dyes. Reeves et. al. (1992), Pelegrini et. al. (1999), Chun et. al. (2003) and Hinda et. al. (2002) and Daneshwar et. al. (2003) have used this technology for industrial wastewaters containing Azo-dyes. Rao et. al. (2003) has investigated the influence of common metallic ions on the slurry phase reactor performance.

Deposition of thin films initially had remained in the realm of patents. Natrajan et. al. (1998) applied spray pyrolysis technology for film deposition. Loddo et. al. (1999) have developed a combination of Rutile and Anatase $\mathrm{TiO}_{2}$ based film to degrade 4-Nitro-Phenol. Mills et. al. (2003) worked on deposition of thin films. Gullierd et. al. (2002) have described Sol-gel technology for preparation of Titanium film. The doping of Titania to enhance its reactivity in the visible light has also been studied by researchers. Komova et. al. (2000) have used Copper to dope the Titania and increased the photo-catalytic activity. The film based reactors are also widely being used by researchers to degrade complex organics. Noorjahan et. al. (2003) have used thin film based reactor to degrade H-acid.

Researchers have attempted to estimate the photonic efficiency of this photon-driven process. Serpone et. al. (1999a) and Serpone et. al. (1999b) have described the method of estimation of photonic efficiency and quantum yield also.

The developments in the photo-catalysis technology had been quite rapid and diversified in recent years. Chang et. al. (2010) has presented a review of recent developments in photo-catalysis technology. They have highlighted the emerging fields of research in this arena.

\section{PROPOSED METHODOLOGY}

$\mathrm{pH}$ has a very profound effect on reaction rate. Hence it needs to be optimized at the initial stage. The $\mathrm{pH}$ of wastewaters containing Lignin is near to 9 . The $\mathrm{pH}$ has been varied in the present case by HCL for lower side and by $\mathrm{NaOH}$ for higher side. $\mathrm{pH}$ has been varied from 5.0 to 10.5 for the experimental studies. This is so because too high too low $\mathrm{pH}$ may be impracticable for field applications too. While varying the $\mathrm{pH}$, the catalyst concentration and Lignin concentration is kept as constant. Experimentations have been conducted to degrade the Lignin using different $\mathrm{pH}$ ranges in the Photocatalytic slurry phase reactor. The effect of $\mathrm{pH}$ on COD removal rate is depicted in the Graphs. Thus the $\mathrm{pH}$ has been optimized. This $\mathrm{pH}$ has been maintained throughout the experimentations. Catalyst suspensions are prepared with different concentrations and their transmissivity has been measured. Catalyst concentration in the slurry phase photo-catalytic reactor is very important parameters that affect the reaction rate. However, the catalyst concentration also causes scattering of light and their by reduces the light available which is the driving force of the photo-catalytic reaction. Hence there is an optimum concentration of catalyst which gives 
the highest reaction rate. It will be dependent upon the intensity of light source. Hence, the light source intensity during experimentation is kept constant. It is practicable to work out the optimum catalyst concentration with reference to this intensity of light. Thus the optimum concentration of catalyst considering the radiation source available is established. This concentration is used as the optimum concentration.

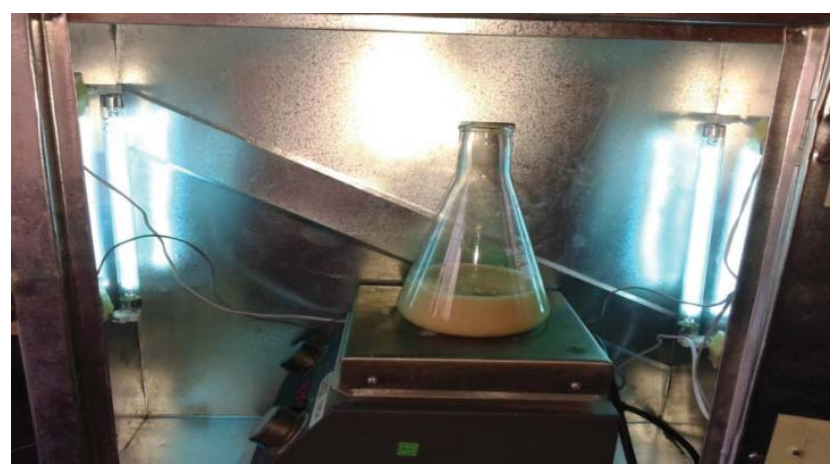

Figure1: Experimental setup showing the slurry phase Photocatalytic UV Reactor

\section{RESULT}

4.1 Graphs showing effect on COD reduction of the Photo catalytic reactor at varying $\mathrm{pH}$

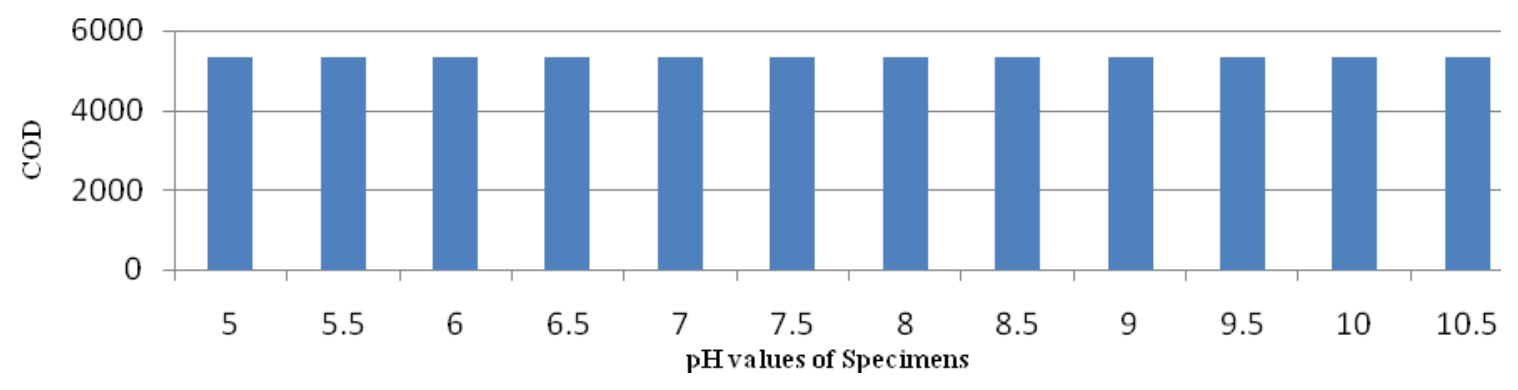

Graph 1: Variation in COD at different $\mathrm{pH}$ values for Lignin-water media at initial time.

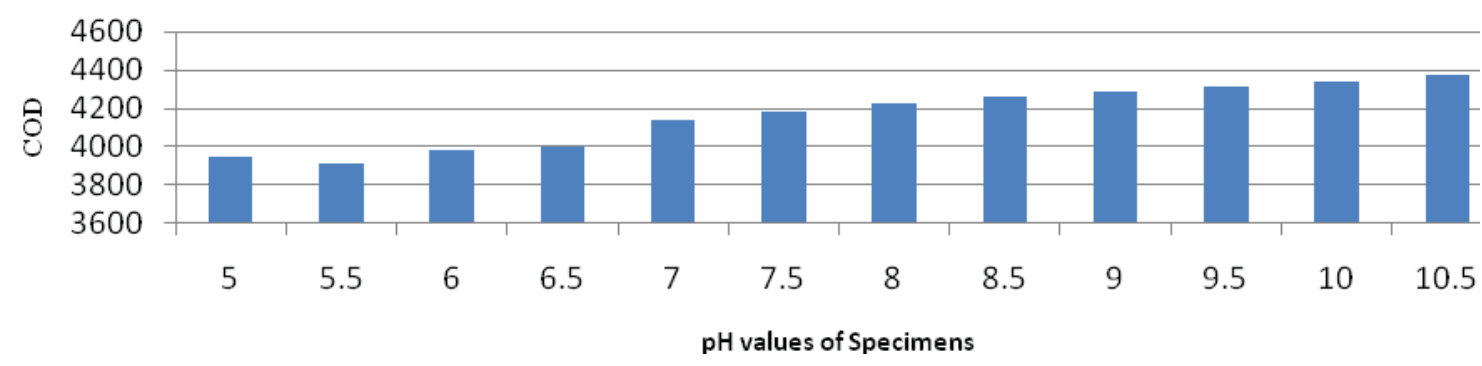

Graph 2: Variation in COD at different $\mathrm{pH}$ values for Lignin-water media after 30 minutes. 


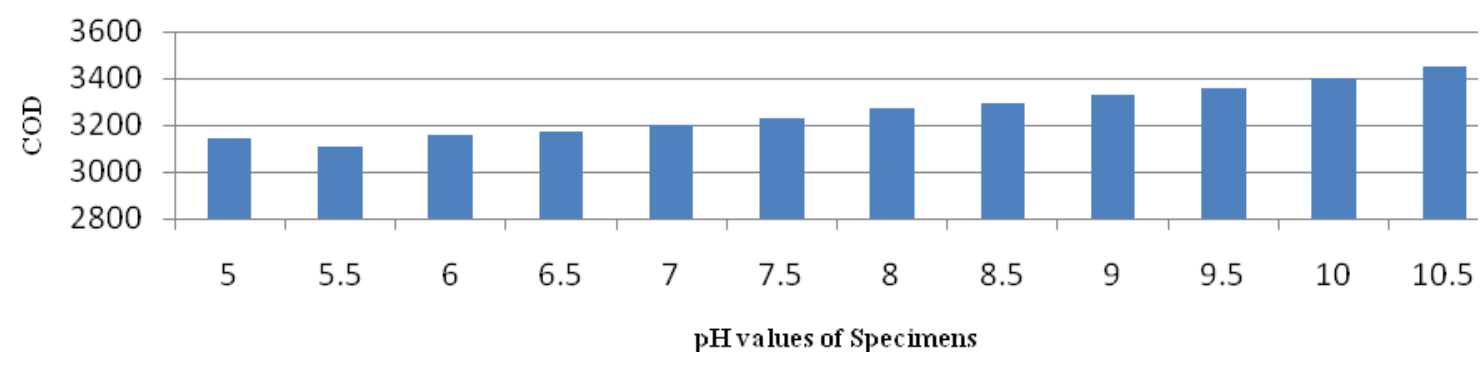

Graph 3: Variation in COD at different $\mathrm{pH}$ values for Lignin-water media after 60 minutes

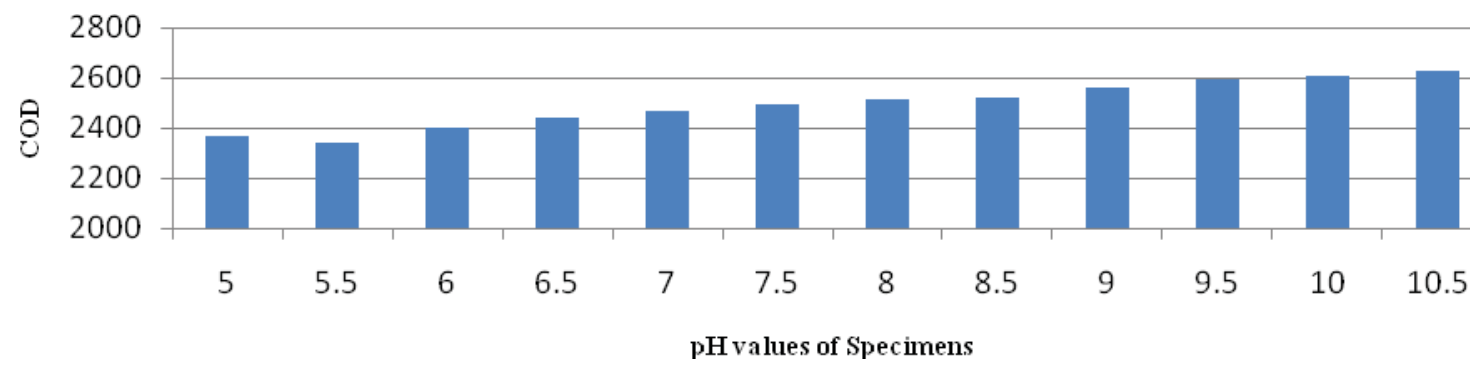

Graph 4: Variation in COD at different $\mathrm{pH}$ values for Lignin-water media after 90 minutes

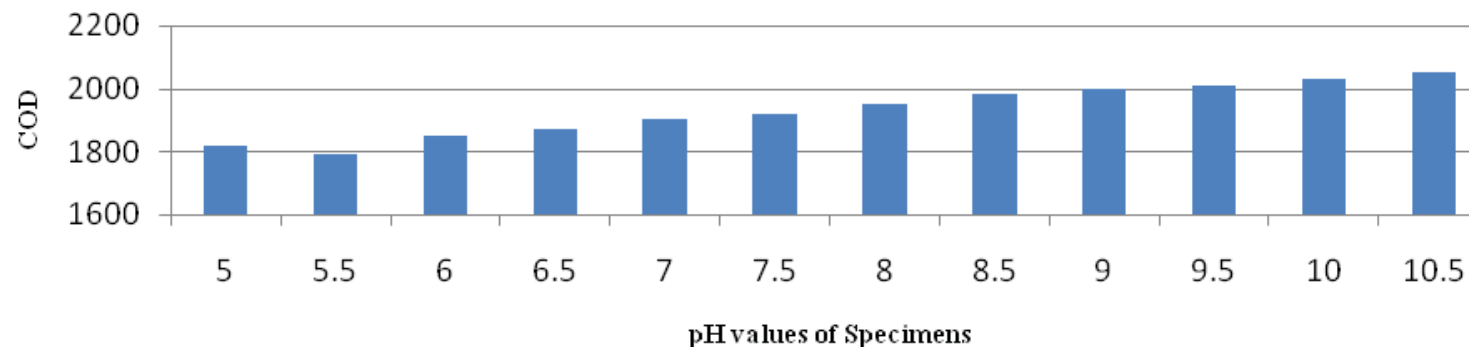

Graph 5: Variation in COD at different $\mathrm{pH}$ values for Lignin-water media after 120 minutes

4.2 Graph showing effect on COD reduction of the Photo catalytic reactor at varying Catalyst concentrations

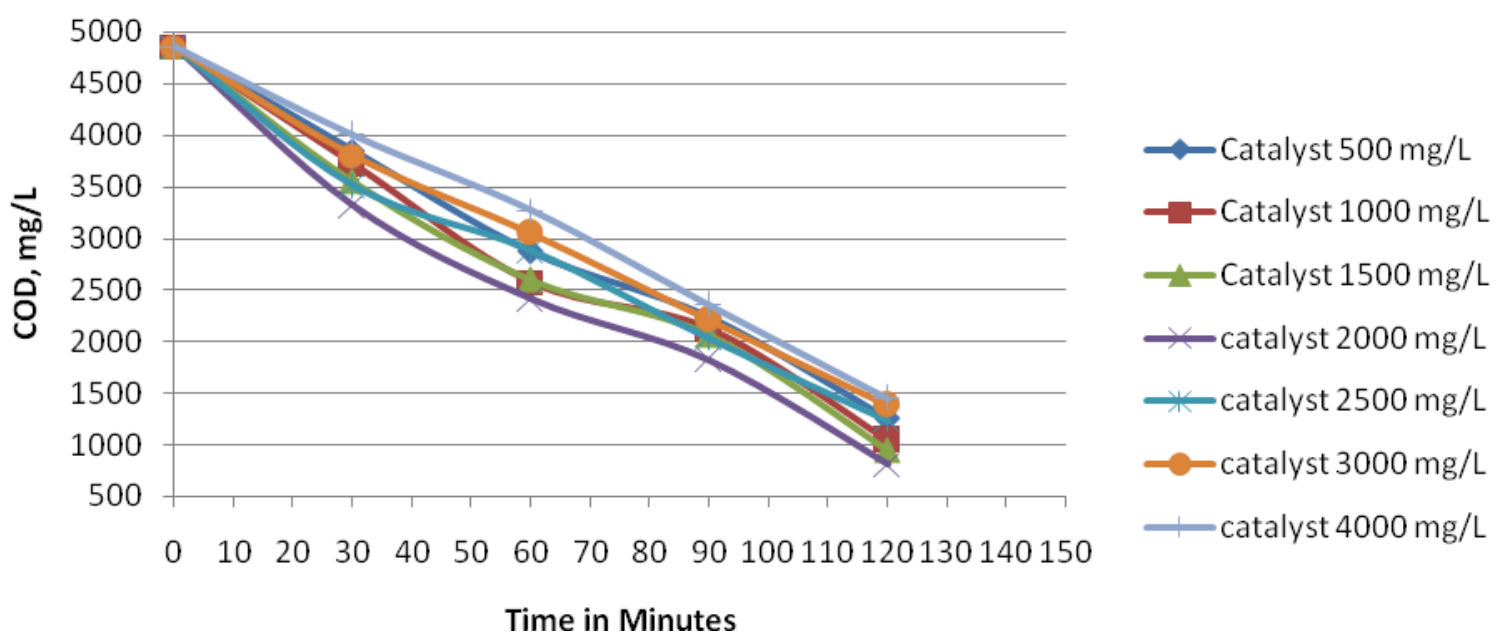

Graph 6: Variation in COD at different Catalyst Concentrations for Lignin-water media w.r.t. Time 


\section{CONCLUSION}

It can be concluded from the present study that the Photo-catalysis can be an emerging area of wastewater treatment technology. The process is effective though, complex and needs rigorous investigations. Experimentations have shown significant effect of $\mathrm{pH}$ variation upon oxidation of Lignin in wastewater via COD tests. From the above experimentations it can be observed that the optimum $\mathrm{pH}$ is 5.5 giving highest oxidation efficiency for Lignin in photo catalytic batch reactor. Catalyst concentration has also shown an influencing factor in the oxidation process as it tends to scatter the light in the slurry and thereby affecting reaction. From above studies it can be concluded that the catalyst concentration of $2000 \mathrm{mg} / 1$ has optimized COD removal for $2 \%$ Lignin-water media when treated for 2 Hours in the Photocatalytic slurry phase reactor. The optimum $\mathrm{pH}$ and optimum concentration of catalyst has been established in the studies carried out. Furthermore, effects of other operational parameters need to be studied.

\section{REFERENCES}

[1] Alberici Rosana M. and Wilson F. Jardim [1997] "Photocatalytic destruction of VOCs in the gas-phase using titanium dioxide". Applied Catalysis B: Environmental 14, 55-68.

[2] Brillas Enric, Eva Mur, Roser Sauleda, Laura Sanchez, Jose Peral, Xavier Domenech, Juan Casado [1998] "Aniline mineralization by AOP's: anodic oxidation, photocatalysis, electro-fenton and photoelectro-fenton processes". Applied Catalysis B: Environmental 16, 31-42.

[3] Augugliaro Vincenzo, S. Coluccia, V. Loddo and M. Schiavello [1999] "Photocatalytic oxidation of gaseous toluene on anatase TiO2 catalyst: mechanistic aspects and FT-IR investigation". Applied Catalysis B: Environmental 20, 15-27.

[4] Cao Lixin, Zi Gao, Steven L. Suib, Timothy N. Obee, Steven O. Hay and James D. Freihaut [2000] "Photocatalytic oxidation of toluene on nano-scale TiO2 catalysts: studies of deactivation and regeneration“. Journal of catalysis 196(2), 253-261.

[5] Alex H. C., Chak K. Chan, John P. Barford and John F. Porter [2003] "Solar photocatalytic thin film cascade reactor for treatment of benzoic acid containing wastewater". Water Research 37, 1125-1135.

[6] Pal Bonmali and Maheshwar Sharon [2000] "Photodegradation of polyaromatic hydrocarbons over thin film of TiO2 nanoparticles; a study of intermediated photoproducts". Journal of Molecular Catalysis A: Chemical 160, 453-460.

[7] Alhakimi Gamil, Lisa H. Studnicki and Muftah Al-Ghazali [2003] "Photocatalytic destruction of potassium hydrogen phthalate using TiO2 and sunlight: application for the treatment of industrial wastewater". Journal of Photochemistry and Photobiology A: Chemistry 154, 219228.

[8] Alpert Daniel J., Jeremy L. Sprung, James E. Pacheco, Michael R. Prairie, Hugh E. Reilly, Thomas A. Milne and Mark R. Nimlos [1991] "Sandia National Laboratories' work in solar detoxification of hazardous wastes". Solar Energy Materials 24, 594-607.

[9] Ananta S., R. Tipakontitikul and T. Tunkasiri [2003] "Synthesis, formation and characterization of zirconium titanate (ZT) powders". Materials Letters 57, 2637-2642.

[10] Carey J. H., Lawrence J. and Tosine H. M. [1976] "Photo-dechlorination of polychlorinated biphenyls in the presence of titanium dioxide in aqueous solutions" Bulletin in Environment Contamination Toxicology 16(6) 697-701.

[11] Leport P. G., Vlcek A. and Langford C. H. [1993] “The photocatalytic oxidation of propanol by TiO2”. In Photo-catalytic Purification and Treatment of Water and Air. Ollis D. F. and Al-Ekabi H. (Eds.), Elservier, Amsterdam. 373-385.

[12] Domenech X. [1993] "Photocatalysis for aqueous phase decontamination: is TiO2 the better choice". In Photocatalytic Purification and Treatment of Water and Air, Ollis D. F. and Al-Ekabi H. (Eds.) Elsevier, Amsterdam 337-351.

[13] Bedford J., Klausner J. F., Goswami D. Y., and Schanze K. [1994] "Performance of non-concentrating solar Photocatalytic oxidation reactors, Part II: Shallow pond configuration". Journal of Solar Energy Engineering, ASME 116(1), 8-13.

[14] Zhang Lianfeng, Tatsuo Kanki, Noriaki Sano and Atsushi Toyoda [2001] "Photocatalytic degradation of organic compounds in aqueous solution by a TiO2 coated rotating drum reactor using solar light". Solar Energy 70(4), 331-337.

[15] Muradov Nazim Z., Ali T-Raissi and Michel R. Kemme [1994] "Solar detoxification of nitroglycerine-contaminated water using immobilized titania". Solar Energy 52(3), 283-288.

[16] Noorjahan M., M. Pratap Reddy, V. Durgakumari, P. Boule and M. Subrahmanyam, [2003] "Photocatalytic degradation of H-acid over a novel TiO2 thin film fixed bed reactor and in aqueous suspensions". Journal of Photochemistry \& Photobiology A: Chemistry 6211, 1-9.

[17] Serpone Nick and A. Salinaro. [1999a] "Terminology, Relative Photonic efficiency and quantum yields in heterogeneous photocatalysis Part I: suggested protocol (Technical Report)". IUPAC, Commission on photochemistry. Pure Applied Chemistry 71, 303-320.

[18] Serpone Nick and A. Salinaro. [1999b] "Terminology, Relative Photonic efficiency and quantum yields in heterogeneous photocatalysis Part II: experimental determination of quantum yields (Technical Report)". IUPAC, Commission on photochemistry. Pure Applied Chemistry 71, 321-335.

[19] Chang N M, Jin B, Christopher W K, Chris Saint (2010) Recent developments in photo-catalytic technology: a review, Water Research, 44, 2997-3027 